\title{
The Impact of Undiagnosed Synaesthesia on the Interpretation of Structural and Functional MRI Images Connectivity Maps and Resulting Diagnoses
}

\author{
Nourhan Zayed. \\ Computers and Systems Department, Electronics Reseach Institute, Giza, Egypt \\ *nourhan@eri.sci.eg
}

\begin{abstract}
Synathesia is a condition in which stimulation of a sensory modality triggers another sensation in the alike or an unalike sensory modality. Currently, synaesthesia is deemed a neurological condition that engages unwanted transfer of signals between brain regions from one sense to another "crosstalk activation". The probability that undiagnosed synaesthesia may impact the results of structural magnetic resonance imaging (MRI), Diffusion Tensor imaging (DTI), functional magnetic resonance imaging (fMRI) and resting state connectivity studies is high, given the multiple anatomical and functional connections within the brain. In this paper, the currently available literature to mark which sensations adjured by synaesthesia and how could this impact MRI different modalities. Our study found that synaesthesia can have an opaque impact on fMRI studies of sensory, memory and cognitive functions, and there is testimony to suggest structural connections in the brain are also mutated DTI measurements especially, it shows enhanced structural connectivity for synesthetes between brain regions, higher Fractional anisotropy (FA), as well as increased in the white matter integrity between some regions.. Given the low dispersal of synaesthesia, the likelihood of synaesthesia being a perplexing factor in DTI, fMRI studies of patient groups is small; however, determining the existence of synaesthesia is paramount for investigating individual patients especially Shizoherenia, and autistic patients.
\end{abstract}

\section{Indexing terms/Keywords}

Syanaesthesia, Structural MRI, Diffusion tensor imaging, Functional MRI (fMRI), Resting state fMRI, Brain connectivity.

\section{INTRODUCTION}

Synaesthesia, known for sundry hundred years [1]-[4], is a placement in which one kind of stimulation recalls a secondary sensation in the same or different sensory modality (e.g., Syneasthete: each time a he/she visualize a colored text he/she hears sounds, or whenever the rolling stones come on radio, visions of silver triangles appear in his/her head). The anatomy and inter- regional connectivity of the brains of synaesthetes vary from those of non-synaesthetes is reported [5]. Hence, anatomical, structural, or functional studies of the brain may be impacted if they include people with undiagnosed synaesthesia.

Magnetic resonance imaging (MRI) modalities, such as diffusion tensor imaging (DTI) [6] and functional magnetic resonance imaging (fMRI) [7], have been widely adopted to diagnose neurological diseased patients' in clinical routine by quantifying neurological disrupt through immediate observation of tissue. MRI modalities have the advantage providing high-resolution imaging as well as clear tissue contrast. In addition, they provide no chance of ionizing radiation exposure. Different MRI techniques obtain contrast through their sensitivity to the microstructure of biological tissues; DTI is susceptible to interstitial water diffusion through tissue [6], whereas fMRI is susceptible to changes in blood oxygen levels dependent (BOLD) contrast in response to specific tasks that engage cognitive, motor and sensory processing [7]. DTI and $\mathrm{fMRI}$ are serviceable for identifying and assessing neurological disorders; Through, combining these techniques provide extra information about brain arrangement and inter-regional linkage and how these are disrupted in the presence of neurological disease.

More recently, networks of brain regions involved in a task have been identified by cross- correlation analysis of the fluctuations in activity across brain regions during task execution [8]. A significant correlation between regions indicates they are working in synchrony to execute the task; that is, they are functionally connected. Thus, the level of significance of the correlation has been termed functional connectivity. Even more intriguing is the observation that in many cases these same brain regions 40 exhibit significant correlations even when no specific task is being performed (called restingstate connectivity).

Romke et al. [5] have provided a preliminary study using DTI that validates their hypothesis that hyper connectivity causes the added sensations in the synaesthesia and they found an evidence that the increased structural connectivity is associated with the presence of grapheme-color synaesthesia and has a role in the subjective nature of synaesthetic experience. Pathways to see music is shown by Zamm et al. [9], who found that there is a white matter integrity within the right inferior fronto-occipital fasciculus (IFOF) and it was presumedly greater in synesthetes than controls. Furthermore they showed that white matter integrity in synesthetes was correlated with scores on audiovisual experiments of the Synesthesia group especially in the white matter underlying the right fusioform gyrus. Given this potential impact of synaesthesia on the interpretation of DTI and fMRI measurements, this motivates us to undertake a more general study in order to understand the possible impact of synaesthesia on these MRI imaging modalities. Our hypothesis is given that synaesthesia impacts underlying brain structure and brain function, undiagnosed synaesthesia should be considered a general confounding factor in the interpretation of DTI, fMRI and other MRI modalities.

Recently, fMRI has been used to specifically measure brain function and related changes in cognition associated with certain classes of synaesthesia [10]-[13] (see for example, Figure 1). Tomoson et al. reconnoiter functional connectivity of color and grapheme rareas during a synesthesia-inducing fMRI paradigm including rest, auditory grapheme stimulation, 
and audiovisual grapheme excitation. [14]

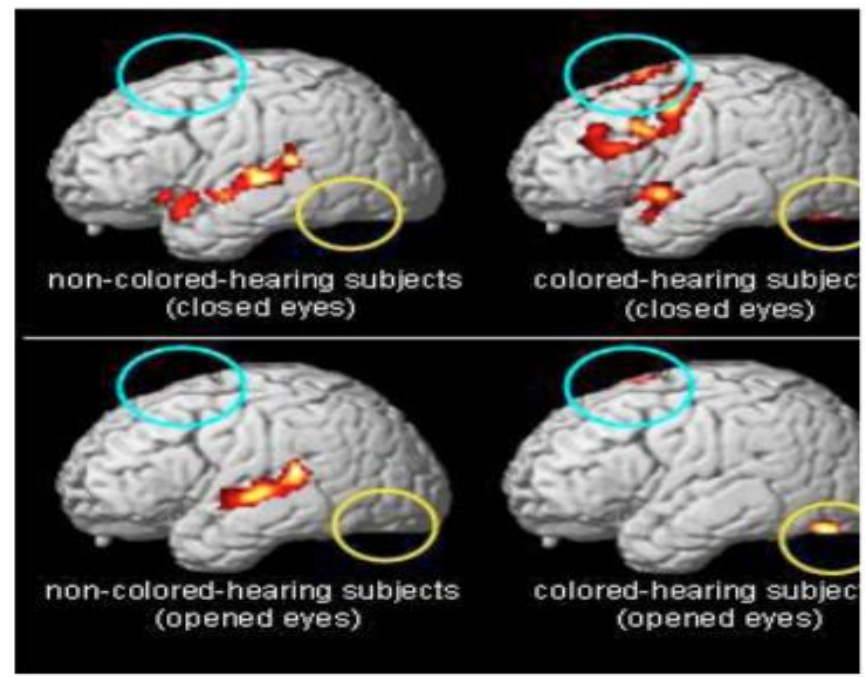

Fig 1: fMRI data illustrating activation of more areas in the brains of synaesthetes compared to normal (adapted from [10]).

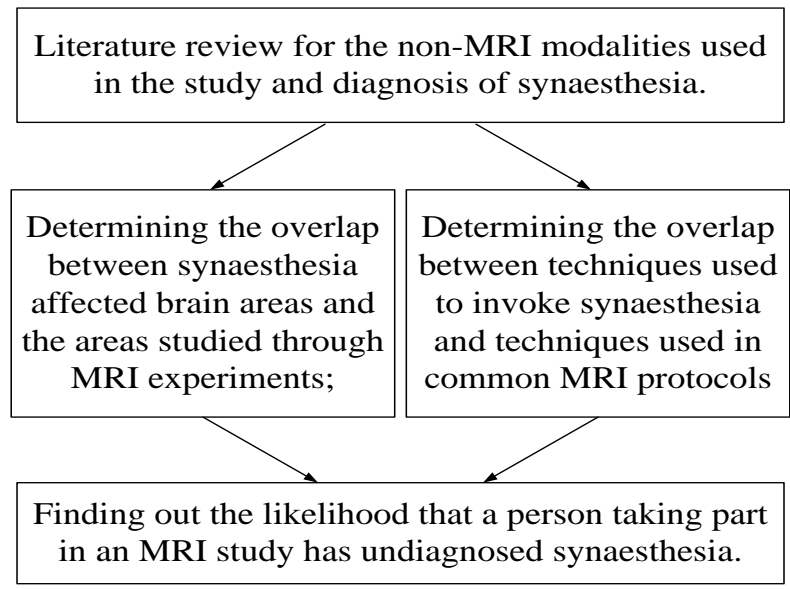

Fig 2: The proposed research methods strategy.

\section{MATERIALS AND METHODS}

Data mining was undertaken on the existing literature on the study and diagnosis of synaesthesia using non-MRI modalities, the research used methods are shown in Figure 2. We hoped to determine:

(i) If brain regions currently recognized as affected by synaesthesia overlap those commonly studied with MRI structural and/or functional imaging;

(ii) If the experimental techniques used to invoke synaesthesia overlap with techniques used in common fMRI protocols, and

(iii) The likelihood that undiagnosed/diagnosed synaesthesia impact the interpretation of MRI different modalities data.

\section{RESULTS}

Zayed et al. [15] showed the following examples that illustrates the impact of synaesthesia on every day activities:

(i) Figure. 3A provides a graphic artist's interpretation of how the hearing of sound causes a synaesthete to visualize colored text.

(ii) Lisa, a synaesthete (graphemes), conveys many crossed associations between letters, numbers, and other symbols in the form of (reshowing) colors, personalities, sexes, and sometimes textures, as seen in Figure. 3B and Table 1.

(iii) Eagleman et al. [16] stresses that the blending of senses synesthetes experience is not a hallucination. To research this type, they developed a virtual reality program to allow people to place all of their weekdays, months, or numbers into a three- dimensional space and sort them in relationship to their body space. From their research study, synesthesia 
appears to be ancestral; the gentic test suggests that colored sequence syhtnehesia is linked to a gene in the $16 \mathrm{q} 12.2$ 23.1 regions.

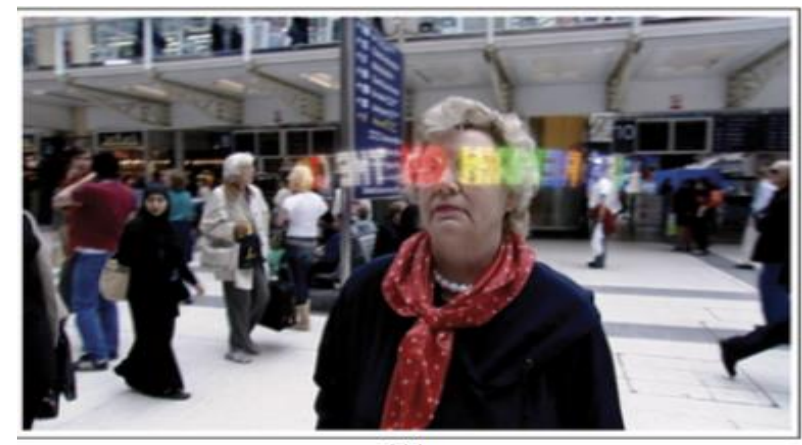

(A)

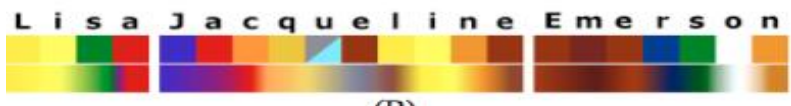

(B)

Fig 3: (A) A graphic artist's interpretation of the reports of projector synaesthete DL, for whom speech produces visualized colored text that is projected into space. (B) An illustration of how a color graphemes synaesthete sees her name as individual letters and as a full word.

The specific colors that appear in response to reading black text on a white background are prevalent across many synaesthetes, suggesting a joint anatomical substrate within the brain. Synaesthetes are equipped with more connections between neurons has been suggested by Baron-Cohen [17], and that the usual pattern of operation in the brain is deviated. We understand this observation has a number of possible MRI and brain connectivity related impacts:

(i) fMRI tasks may activate more areas in the brain than expected.

(ii) The increased neural connectivity between synaesthesia connected areas may command to changes in brain tissue characteristics that could appear as different image textures in DTI and affecting the DTI measurements the FA values that indicates the white matter integrity.

The limbic system is primarily responsible for synesthetic experiences are suggested by Cytowic [18]. Since the regulation of emotional responses is uttered by brain structures in the limbic system, then we interpreted that emotional vigilance may spoil feature binding in working memory studies used over and over in fMRI studies, as for example in studies of schizophrenia [19], [20] and Autism [21].

For example, in a post-surgical study of anterior temporal lobectomy, fMRI studies using tasks involving facial and vocal expressions and word recognition, there is also potential for misinterpretation of the results because of the engagment between words and emotional arousal in some synaesthetes [22]. Other example is the impacting that could occur on Alzheimer fMRI experiments [23] where parietal, frontal and occipital-temporal cortical regions and primary visual cortex in the brain are triggered.

Special textures have been reported in MRI images associated with specific gene types present in tumors [24], Eagleman et al. in their research genetic analysis suggests that colored sequence syhtnehesia is linked to a gene in the $16 q 12.2-$ 23.1 regions, and states that synesthesia appears to be heritable. Given its genetic ingredient, it is possible that synaesthesia will also present textures in specific regions of DTI and fMRI images.

Table 1. This table details the plenty of brain responses that occur upon a synaesthete's reading of black text on a white background. These effects can be expected to confound the interpretation of certain DTI, fMRI, and/or brain connectivity studies. (Synaesthesia Case Study)

\begin{tabular}{|l|l|}
\hline Number/ Character & \multicolumn{1}{|c|}{ Synaesthete Experience } \\
\hline 0 & $\begin{array}{l}\text { colour: black or white. Unlike the letter 'o', which } \\
\text { appears white and vanishes from the page, the } \\
\text { number '0' "comes in and out of being, so to speak, } \\
\text { like it is there and then it isn't". } \\
\text { sex: male } \\
\text { age: in his forties, but also kind of seems ageless in } \\
\text { a way } \\
\text { personality: intelligent, but keeps himself } \\
\text { separated from the others out of a sense of duty. }\end{array}$ \\
\hline 3 & $\begin{array}{l}\text { colour: medium-light green } \\
\text { sex: female } \\
\text { age: not too old, but basically an indefinable age }\end{array}$ \\
\hline
\end{tabular}




\begin{tabular}{|l|l|}
\hline & personality: grandmotherly and responsible \\
\hline $\mathrm{X}$ & $\begin{array}{l}\text { colour: slightly dark red } \\
\text { sex: of mixed sex, but mostly female }\end{array}$ \\
\hline & $\begin{array}{l}\text { colour: black } \\
\text { sex: male }\end{array}$ \\
\hline
\end{tabular}

When investigating individual patients, determining the presence of synaesthesia is important. Also fMRI and DTI researchers should be circumspect that reports of synaesthesia are more common amongst certain genetic and gender specific groups. For example, women synaesthetes in the U.S. inhabitance outnumber males by a ratio of 3:1 [25], while a female to male ratio of $8: 1$ is found in U.K. [26]. Synaesthesia remains basically a self-reported condition, and the confusion of reporting oneself as being "different" may be responsible for the unclear accepted prevalence of synaesthesia in the general inhabitance. Up until recently, synaesthesia was thought to occur in one person out of 25,000; recent assessments range from between 1 in 200 to 1 in 2000 [27] depending on the study performed [28], [29]. Sagiv et al. [30] stated that the estimate concerning the recrudescence of synaesthesia vary widely because the spread estimation was based on the number of people responding to a newspaper advertisement, many cases were probably missed either because they did not see the ad or saw it but choose not to respond. Some researchers think the prevalence (for a mild form) is much higher [27]-[31].

Rocca et al. [32] compared a group of 13 synesthetes with a group of 11 controls. They used the voxel-based morpometery manifesting changes increase in the gray matter volume, looking in the DTI structural parameters of nerve fibres, they find multiple regions of increases FA in synesthetes compared to controls which interpreted as extra visual Functional and structural connections abnormalities [Figure 4].

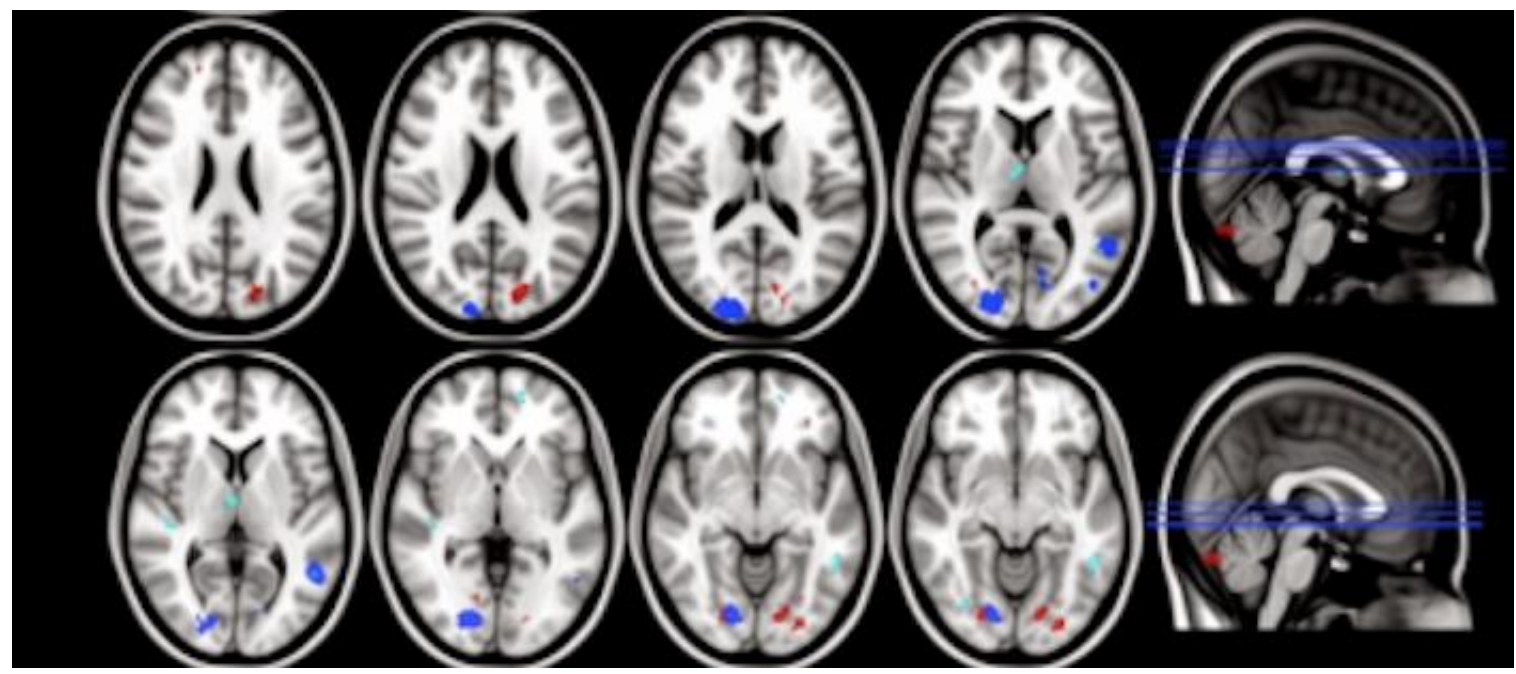

Fig 4: A synaesthete DTI structural parameters, red indicates the grey matter volume increase in the, light blue for increase in white matter volume, dark blue for white matter FA increases (adapted).

In Table 2 we summarize how a number of specific synaesthesia types may impact upon DTI, fMRI, resting state connectivity studies when tasks intended to invoke a specific sensation unintentionally provoke a second sensation.

\section{CONCLUSION}

Our data mining exercise on the existing literature, summarized in Figure 5, indicates that fMRI and DTI images and resting state brain connectivity maps may be influenced by changes in brain structure associated with synaesthesia in a number of ways that are not currently recognized in the literature. Given that this effect is well documented, yet probably under-reported because of the social perplexity connected with self diagnosed disease, we leave the reader with two immediate proposal for further technical analysis of how the impact of synaesthesia manifests in DTI and fMRI images. (A) Given the wide range of circumstance under which this type of confounding factor could be detected, it is important that researchers do not set a false positive label on undiagnosed synaesthesia or simply dismiss the effect as noise; and (B) To better understand the prevalence of synaesthesia, a "self report" [33], [34] be added as a simple diagnostic exam for synaesthesia as part of pre or post MRI protocols. In Future researchers may in a hopeful manner tell whether these kinds of cortical deactivations really are an important component of the synaesthetic experience. Meanwhile, our findings add to a multiple different set of neuroimaging findings, which have yet to definitively clinch the neural correlates of the synaesthetic experience. Perhaps expecting a single mechanism is an error, if the condition is really heterogeneous we may need some other means of investigations. 
Table 2. The Impact of Synaesthesia Types on DTI, fMRI, and/or Resting state connectivity maps

\begin{tabular}{|c|c|c|c|}
\hline $\begin{array}{l}\text { Synaesthesia } \\
\text { Type }\end{array}$ & First Sensation & The Joint Sensation & $\begin{array}{c}\text { Effect in DTI, fMRI, and/or Resting state } \\
\text { connectivity maps }\end{array}$ \\
\hline $\begin{array}{l}\text { Coloured } \\
\text { graphemes } \\
(66.8 \%)\end{array}$ & Visual & Visual & \multirow{4}{*}{$\begin{array}{l}\text { Significant activity in the cerebral cortex } \\
\text { during synesthetic experiences: } \\
\text { a) Impacting on Alzheimer fMRI } \\
\text { experiments where parietal, frontal and } \\
\text { occipital-temporal cortical regions and } \\
\text { primary visual cortex in the brain are } \\
\text { activated. } \\
\text { b) Impacting on resting state connectivity } \\
\text { maps for Asperger Syndrome (Autism } \\
\text { patients) has been showing more } \\
\text { connections in between the visual cortex } \\
\text { regions, the same as for Coloured } \\
\text { graphemes synthestes which is confused } \\
\text { if it is kind of brain plasticity or extra } \\
\text { connections shown in the Autism patients } \\
\text { to compensate some of the deficits in } \\
\text { other functions. } \\
\text { c) Impacting on the DTI as it has been } \\
\text { shown alterations in the FA values and } \\
\text { increase in the white integrity. }\end{array}$} \\
\hline $\begin{array}{l}\text { Coloured pain } \\
(4.4 \%)\end{array}$ & Pain & Visual & \\
\hline $\begin{array}{c}\text { Coloured } \\
\text { personalities } \\
(4.4 \%)\end{array}$ & Persons & Visual & \\
\hline $\begin{array}{c}\text { Coloured touch } \\
(1.9 \%)\end{array}$ & Touch & Visual & \\
\hline \begin{tabular}{|c|} 
Coloured \\
musical sounds \\
$(14.5 \%)$ \\
Coloured \\
general sounds \\
$(12.1 \%)$ \\
Vision hearing \\
$(1.1 \%)$
\end{tabular} & Hearing & Visual & $\begin{array}{l}\text { a) Since listening to music or certain } \\
\text { words can be used in fMRI imaging, then } \\
\text { synesthesia may also activated the visual } \\
\text { cortex. Also it is confused with the } \\
\text { plasticity or the kind of compensation } \\
\text { occurs in optic neuritis /multiple sclerosis } \\
\text { patients (appears in resting state } \\
\text { connectivity maps). b) Impacting on } \\
\text { resting state connectivity maps for } \\
\text { Asperger Syndrome (Autism patients) as it } \\
\text { has been shown more connections in } \\
\text { between the visual cortex regions of the } \\
\text { autism patients, the auditory areas and } \\
\text { other brain regions which is the same as } \\
\text { for Coloured general sounds synthestes } \\
\text { so it is confusing if it is kind of brain } \\
\text { plasticity or extra calltalk connections } \\
\text { shown in the Autism patients to } \\
\text { compensate some of the deficits in other } \\
\text { functions or it may be a generation of an } \\
\text { internal sensory in the patients brain } \\
\text { representing deactivation of regions which } \\
\text { might compete for attention or provide } \\
\text { conflicting information. }\end{array}$ \\
\hline $\begin{array}{l}\text { Sound touch } \\
(2.7 \%)\end{array}$ & Touch & Sound & $\begin{array}{l}\text { Patients respond by pressing buttons in } \\
\text { the fMRI experiments. The cross linkages }\end{array}$ \\
\hline $\begin{array}{l}\text { Coloured touch } \\
(1.9 \%) \& \text { Vision } \\
\text { touch }(0.8 \%)\end{array}$ & Touch & Visual & $\begin{array}{l}\text { between touch, sound and vision may } \\
\text { introduce unanticipated additional } \\
\text { activations }\end{array}$ \\
\hline
\end{tabular}




\section{Synaesthesia are equipped with more connections between neurons "crossed-wiring"}

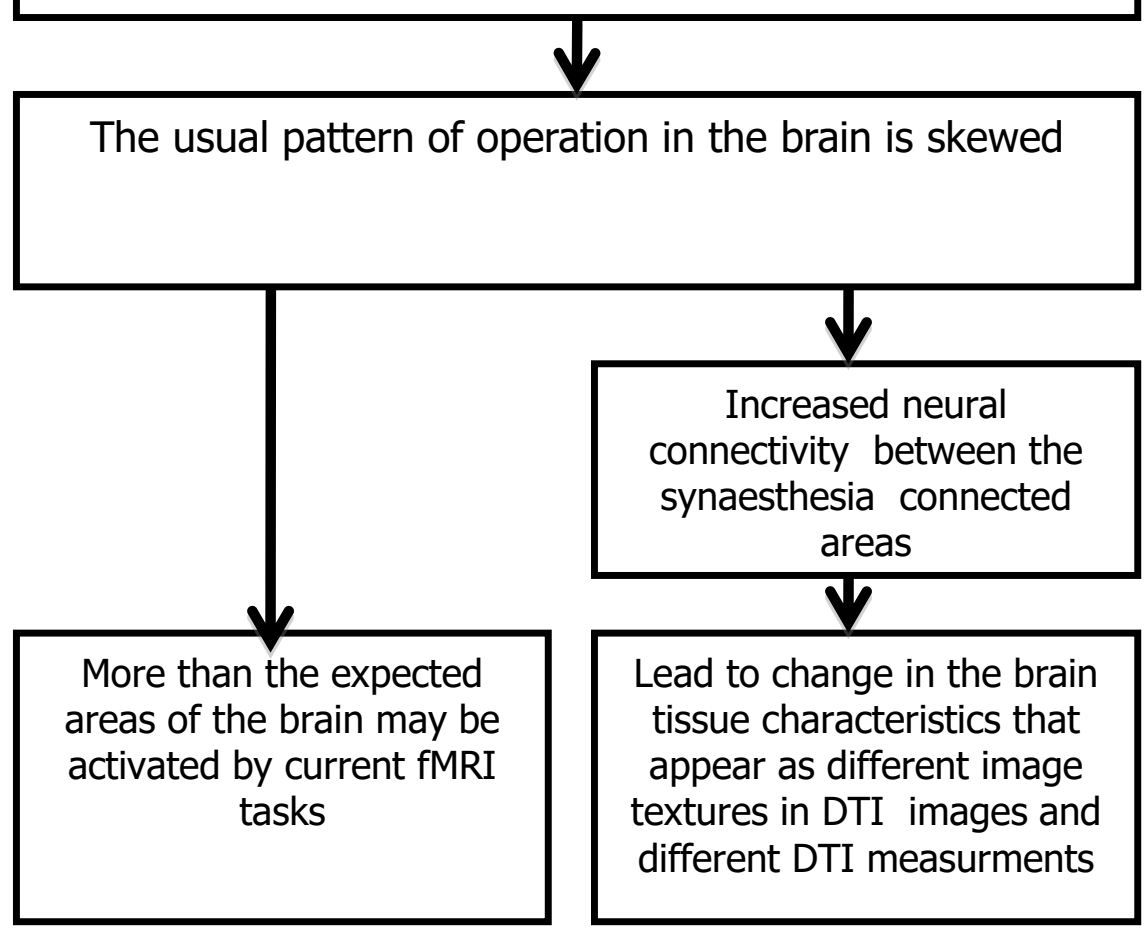

Fig 5: A summary of the impact of synaesthesia on fMRI, DTI, and resting state maps.

\section{REFERENCES}

[1] Cytowic, R. 1989 A Union of the Senses. New York: Springer-Verlag.

[2] Ward, J., and Mattingly, J. 2006 Synaesthesia: an overview of contemporary findings and controversies, Cerebral Cortex, vol. 42, pp. 129-136.

[3] Konch, D., Gianotti, L., Mohr, C., and Brugger, P. 2005 Synesthesia: when colors count, Cognitive Brain Research, vol. 25 , pp. 372-374.

[4] Lucas, V. 2004 What does synaesthesia mean? ACM Siggraph Reports, Available:www.siggraph.org/conferences/reports/s2004/exhibits/syna- esthesia.html. (Accessed date August,5 2016)

[5] Rouw, R., and Steven, H. 2007 Increased structural connectivity in grapheme-color synesthesia, Nature Neuroscience, vol. 10 , pp. $792-797$.

[6] Gillard, J., Waldman, A., and Barker, P. 2005 Clinical MR Neuroimaging Diffusion, Perfusion, Spectroscopy. Cambridge University Press, sec. 1.

[7] Buxton, R., and Gillard, J. 2002 Introduction to functional Magnetic Resonance Imaging Principles and Techniques. Cambridge University Press.

[8] ROGERS, B., MORGAN, V., NEWTON, A., and GORE, J. 2007 Assessing functional connectivity in the human brain by fMRI. Magn Reson Imaging, Vol. 25, pp. 1347-57.

[9] Zamm, A., Schlauga, G., Eagleman, D., and Loui, P. 2013 "Pathways to seeing music: Enhanced structural connectivity in colored-music synesthesia, Neurolmage, vol. 74: pp. 359-366.

[10] Beeli, G., Esslen, M., and Jancke, L. 2007 Time course of neural activity correlated with colored-hearing synesthesia, Cerebral Cortex, vol. 10, pp. 1093-1099.

[11] Takahashi, R., Fujisawa, X., Nagata, N., Sugio, T., and Inokuchi, S. 2006 An fMRI study of Synesthesia: Brain activity in colored-hearing by listening to music, IPSJ SIG Technical Reports, vol. 90, pp. 105-108.

[12] Simner, J. 2006 Beyond perception: synaesthesia as a psycholinguistic phenomenon,Trends in Cognitive Science, vol.11, pp. 23-29. 
[13] Steffie, N., Manjari, N., Genevera, I., and Eagleman, M. 2013 Neural Networks of Colored Sequence Synesthesia, The Journal of Neuroscience, vol. 33(35): pp. 14098-14106.

[14] Nunn, J., Gregory, L., Barmmer, M., Williams, S., Parslow, D., Morgan, M., Morris, R., Bullmore, E., Cohen, S., and Gray, J. 2002 Functional magnetic resonance imaging of synesthesia: activation of V4/V8 by spoken words," Nature Neuroscience, vol. 5, pp. 371-375.

[15] Zayed, N., Goodyear, B., and Smith, M. 2008 Is undiagnosed synaesthesia a confounding factor in the interpretation of MRI images?, 30th Annual International Conference of the IEEE Engineering in Medicine and Biology Society, Vancouver, BC, pp. 5778-5781.

[16] Tomson, S., Avidan, N., Lee, K., Sarma, AK., Tushe, R., Milewicz, DM., Bray, M., Leal, S., and Eagleman, D. 2011 The genetics of colored sequence synesthesia: Suggestive evidence of linkage to $16 q$ and genetic heterogeneity for the condition, Behavioural Brain Research, vol. 223,pp.48-52.

[17] Cohen, S. 1996 Is there a normal phase of synaesthesia in development, Psyche, vol. 2.

[18] Cytowic, R. 1995 Synesthesia: phenomenology and neuropsychology a review of current knowledge, Psyche, vol. 2, pp. 10-27.

[19] Mather, M., Mitchell, K., Raye, C., Novak, D., Greene, E., and Johnson, M. 2006 Emotional arousal can impair feature binding in working memory, Journal of Cognitive Neuroscience, vol. 18, pp. 614-625.

[20] Smilek, D., Dixon, M., Cudahy, C., and Merikle, P. 2002 Synesthetic color experiences influence memory, American Psychological Society, vol. 13, pp. 548-552.

[21] Koshino, H. $2008 \mathrm{fMRI}$ investigation of working memory for faces in autism: visual coding and underconnectivity with frontal areas, Cerebral cortex, vol. 18.2, pp. 289-300.

[22] Brierley, B., Medford, N., Shaw, P., and David, A. 2004 Emotional memory and perception in temporal lobectomy patients with amygdala damage, Journal of Neurol Neurosurg Psychiatry, vol.75, pp. 593- 599.

[23] Jing, H., Kuncheng, L., Ki, L., Dexuan, Z., Wei, W., Vanhui, Y., Bin, Y., Baoci, S., and Xiaolin, Z. 2005 Visual attention deficits in Alzheimer's disease: an fMRI study, Elsevier Ireland Ltd: Neuroscience Letters, vol. 385, pp. 18-23.

[24] Phillips, M. 2007 Synaesthesia, Neuroscience for Kids, Available: www. faculty.washington.edu/chudler/syne.html. (Accessed date August,5 2016)

[25] Sperling, J., Prvulovic, D., Linden, D., Singer, W., and Stirn, A. 2006 Neuronal correlates of color-graphemic synaesthesia: a fMRI study, Cortex, vol. 42, pp. 295-303.

[26] Brown, R., Zlatescu, M., Cairncross, J., and Mitchell, J. 2005 Texture Analysis for Non-Invasive Identification of Brain Tumor Genotype from MRI, Fifth IASTED International Conference on Visualization, Imaging and Image Processing (VIIP), Benidorm, Spain.

[27] Cohen, S., Harrison, J., and Goldstein, J. 1993 Coloured speech perception: is synaesthesia what happens when modularity breaks down? Perception, vol. 22, pp. 419-426.

[28] Fredrick, C. 2016 The science behind the story: the Skeekit-Woogle Test, Analog science fiction and fact, Available: www.analogsf.com/0602/behindthestory2.shtml (Accessed date August,5 2016)

[29] Newell, F., Barnett, K., Bargary, G., Mitchell, K., and Carvin, A. 2015 What is Synaesthesia, Synaesthesia Research Group, Available: www.tcd.ie/Psychology/synres/synaesthesia.html. (Accessed date June,5 2015)

[30] Sagiv, N., and Ward, J. 2003 Cross model interactions: lessons from synesthesia, Progress in Brain Research, vol. 155, pp. 263-275.

[31] Simner, J., Mulvenna, C., Sagiv, N., Taskanikos, E., Witherby, S., Fraser, C., Scott, K. and Ward, J. 2006 Synaesthesia: the prevalence of a typical cross-modal experiences,Perception, vol. 35, pp. 1024-1033.

[32] Rocca, M., Valsasina, P., Pagani, E., Bianchi-Marzoli, S., Milesi, Falini, J. A. 2011 Extra-Visual Functional and Structural Connection Abnormalities in Leber's Hereditary Optic Neuropathy, vol. 6(2).

[33] Crétien, V., and Froger, C. 2003 Personal profiles of color synesthesia: developing a testing method for artists and scientists, Leonardo, vol. 36, pp. 291-294.

[34] Crétien, V., and Froger, C. 2001 Assessing the strength of color synaesthesia in words, music, taste, and odor perception, NeCoSyn Scientific Report, Available: www.synesthesie.nl/pub, 2001. (Accessed date August, 5 2016) 


\section{Author' biography with Photo}

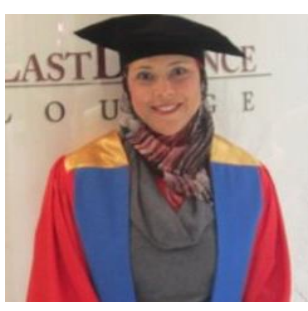

Dr. Nourhan Zayed, has received her Ph.D. in Electrical and Computer Engineering, University of Calgary, Calgary, Canada, where she also worked as a teaching assistant. She worked as an instructor in the Center for Adult and Continuing Education Department, American University in Cairo, Egypt in 2000- 2006. She has been with the Computer Science and Systems Department at Electronics Research Institute, Cairo, Egypt since 1999 where she is currently a Researcher. Along her career, she received several awards and recognitions including the record for research studentship funded by the multiple sclerosis program of the Hotchkiss Brain Institute, Calgary, Alberta, Canada (2008). She is a member of the IEEE, EMBS, ISMRM, and SPIE. Her research interests include medical imaging and in particular MRI and ultrasound, Neuroimaging, Multiple sclerosis and Optic neuritis imaging, multi-dimensional signal processing for biomedical applications, pattern recognition, computer vision, and image processing. 